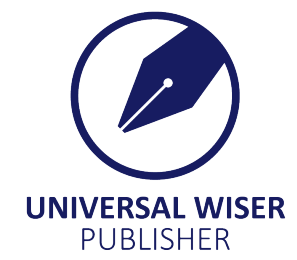

\title{
Management of By-Product Created by Lye-Sodium Brine Purification Method Using Carbonization
}

\author{
Paweł Iwański ${ }^{1 *}$, Bartłomiej Igliński ${ }^{1}$, Grzegorz Piechota $^{2}$ \\ ${ }^{1}$ Nicolaus Copernicus University in Toruń, Department of Chemical Technology, Gagarina 7, 87-100 Toruń, Poland \\ ${ }^{2}$ GPCHEM. Laboratory of Biogas Research and Analysis, Legionów 40a/3, 87-100 Toruń, Poland \\ Email: piwanski@doktrant.umk.pl
}

\begin{abstract}
The article presents carbonization as a method of waste management from the brine sodium-lime method. It was compared with the previously obtained results for the lye-sodium one. Within it, the filtration and washing times were contrasted for treated and non-carbonised samples. For this aim potentiometric titration analysis was used to determine the precipitation's basic components and by-product brine. Scanning electron microscope with energy dispersive X-ray spectrum and diffractographic analysis were used for morphology analysis what allowed to determine the tested samples' composition. It was found that despite significant differences in the time of washing and filtration, the time of these processes is shortened after the suspension has been exposed to carbon dioxide. In both cases the composition allows the waste brine to be recycled to the purification processes and the mixture of calcium and magnesium compounds become alternative raw material. It turned out that in both methods it is possible to utilize the suspension formed.
\end{abstract}

Keywords: brine, lime-sodium method, purification process, carbonization

\section{Introduction}

The problem of waste generation has become a major challenge for our civilization in recent years. The need to process municipal and industrial waste generates enormous costs and is a socio-environmental challenge. In the case of municipal waste, it is necessary to segregate it. When it comes to the case of industrial waste, we usually deal with larger homogeneous waste streams ${ }^{[14]}$.

An example of a process that produces significant waste streams is brine purification. It is obtained by dissolving extracted rock salt in water or by leaching salt deposits directly in the mine. Apart from sodium chloride (97-99\%), rock salt also contains other ingredients. Removal is necessary before using brine in the technological process. The impurities include calcium, magnesium, potassium, iron, silicon, sulphur, carbon, bromine, iodine and other compounds ${ }^{[5]}$.

The removal of calcium and magnesium compounds happens because their presence can lead to the precipitation of compounds inside the apparatus what leads to its damage and product contamination. It is also unfavourable to leave potassium and sulfate compounds. Two methods are used to remove calcium and magnesium from raw brine. The first is lye-sodium (where the precipitation agents are sodium hydroxide and sodium carbonate). The second is lime-sodium (where the precipitation agents are calcium hydroxide-administered in the form of milk of lime and sodium carbonate $)^{[15]}$.

During brine purification, it is important not to dilute the brine due to the introduction of aqueous solutions of sodium hydroxide (lye-sodium method), calcium hydroxide (lime-sodium method) and sodium carbonate. Therefore, the added solutions of precipitation agents are prepared using purified brine at such concentration that no crystallization of sodium chloride occurs. Maintaining the highest possible concentration of sodium chloride in purified brine has a beneficial effect on the purification process. Washing should be carried out in such conditions that calcium carbonate and sodium hydroxide are easy to separate. Their separation is simpler when the particles are large enough ${ }^{[4]}$.

Brine is one of the basic materials used by the industry. It is almost saturated solution containing $300-310 \mathrm{~g} / 1 \mathrm{of}$ sodium chloride and with a density of about $1.2 \mathrm{~g} / \mathrm{cm}^{3}$. It is mainly used in the production of chlorine, caustic soda (sodium hydroxide) and soda ash (sodium carbonate) and in much smaller amounts of hydrochloric acid, chlorides and other chemical compounds. This corresponds to $60-65 \%$ of world salt consumption. Other salt consumption includes: food purpose $15-20 \%$, winter road maintenance $10-15 \%$, the remaining $5 \%$ includes refining, paper, pharmaceutical and other industries. Worldwide salt consumption in various forms per sodium chloride is $230-240$ million tons per year ${ }^{[12]}$. 
Solving the problem of carbon dioxide emissions from anthropogenic sources ${ }^{[9]}$ is currently one of the biggest challenges in science. $\mathrm{CO}_{2}$ is thermodynamically stable, which means that the transformation requires large amounts of energy ${ }^{[17]}$, what hinders and significantly irritates the whole procedure. The use of properly selected catalysts reduces the demand for energy needed to convert $\mathrm{CO}_{2}$ into fuel, but still does not have to guarantee the profitability of such a process ${ }^{[7]}$. The solution is such a transformation that does not need increasing Gibbs energy. The production of carbonate materials with a mineral structure containing $\mathrm{Ca}$ and $\mathrm{Mg}$ does not require the large amounts of energy, what increases the chances of its use for anthropogenic management of $\mathrm{CO}_{2}$. They include, for example, the production of calcium carbonate ${ }^{[3]}$, gypsum $^{[13]}$, calcium chloride ${ }^{[2]}$, or fertilizers ${ }^{[11]}$. Is it possible to apply different storage methods ${ }^{[1]}$, but such solutions require space and use of resources. Brine is added in soda production by the Solvay method. Waste management in the Solvay process can be connected with $\mathrm{CO}_{2}$ utilization ${ }^{[8]}$.

\section{Material and methods}

\subsection{Sample acquisition and preparation}

The research used samples from industrial brine purification installations working in the lime-sodium (with calcium hydroxide and sodium carbonate) technology. Analysis results were compared with previous works where the samples from the lye-sodium installation (with sodium hydroxide and sodium carbonate) were analysed ${ }^{[10]}$. The samples were delivered in packaging protecting them against external conditions, which allowed the concentrations of individual components to remain unchanged. Samples were inventoried in the laboratory.

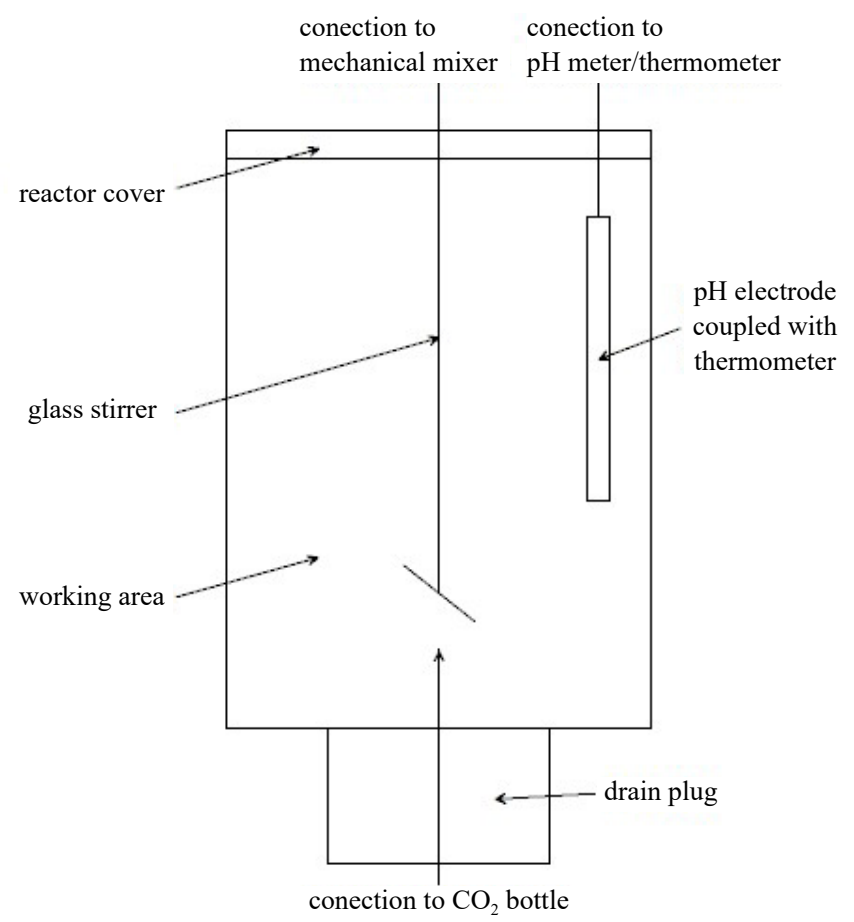

Figure 1. Carbonization reactor

The samples were carbonised, what was carried out in the reactor shown in figure 1. Carbonization was carried out by means of a carbon dioxide (purity of 90-99\%) with a flow rate through the reactor of $10 \mathrm{dm}^{3} / \mathrm{min}$. The reactor was equipped with a mechanical mixer IKA ${ }^{R}$ RW 20 digital equipped with a glass polymer blade mixer due to the favourable corrosion composition ${ }^{[16]}$ of the suspension from the brine purification process. The use of glass elements prevents the corrosion. The rotation speed is $600 \mathrm{rpm}$. Carbonization was achieved until the $\mathrm{pH}$ dropped below 7 . The process was carried out at room temperature. The process was controlled by measuring temperature and $\mathrm{pH}$ using WTW $\mathrm{pH} / \mathrm{cond}$ 340i. The example of carbonization is presented in figure 2 . 
$\mathbf{T}=\mathbf{f}(\mathbf{t})$

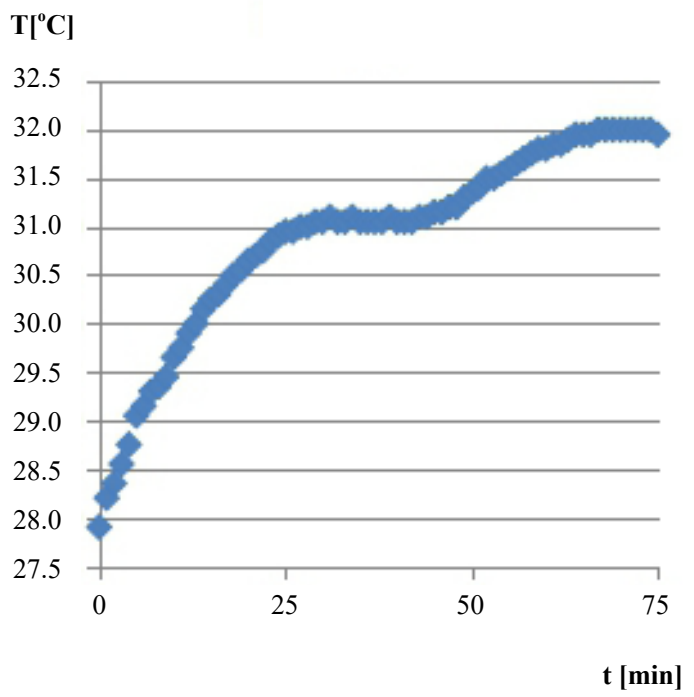

$\mathbf{p H}=\mathbf{f}(\mathbf{t})$

pH

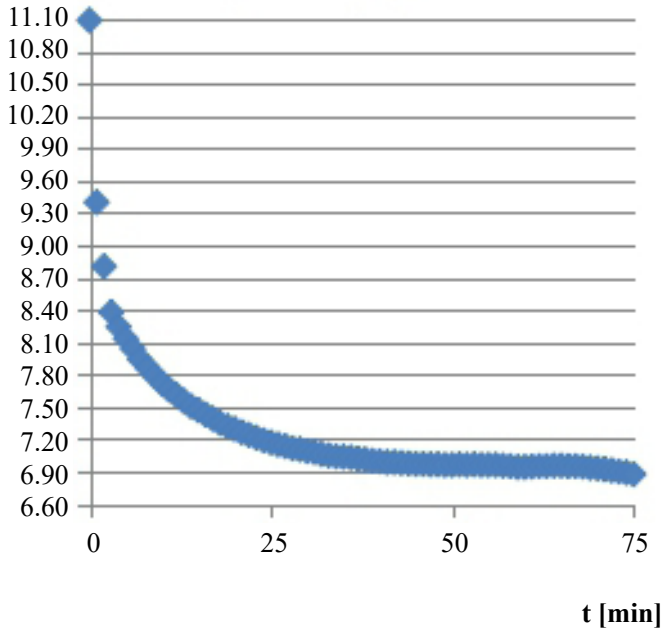

Figure 2. Example carbonization process in functions $T=f(t)$ and $p H=f(t)$ where $T$ is temperature on Celsius, scale $\mathrm{pH}$ is $\mathrm{pH}$ scale and $\mathrm{t}$ is time in minutes

After carbonization, the samples were filtered under negative pressure. $100 \mathrm{~cm}^{3}$ of the homogenized suspension in the cylinder was filtered through a Büchner funnel. A mechanical vacuum pump Rocker 410 was used to create the void. Filter paper Filtrpak type 390 with density $84 \mathrm{~g} / \mathrm{m}^{2}$ was used. The samples were filtered and then washed three times with distilled water in amount of $20 \mathrm{~cm}^{3}$ distilled water, which corresponded to about $2 / 3$ of the filter cake volume. Due to the tendency of the filter cake to crack, further portions of distilled water were added before the filter cake emerged. Thanks to this there was water over the forming cake all the time, what protected it from the risk of cracking. Only the third wash was carried out until the "last drop", which means there were at least 5 minute intervals between drops. In a situation where the cake cracked, the test was repeated. The reference sample was analogically subjected to similar procedures without carbonization. Each time of the filtered and washed was saved. A stopwatch was used for time measurement.

\subsection{Analysis methods}

To calculate the humidity the samples from washed and filtered sodium chloride sludge were taken. The rest of the precipitation was drying on its own. Each subsequent test was conducted with the use of air-dried precipitate. The moisture content was determined. Potentiometric titration method was used to show the $\mathrm{Cl}^{2}, \mathrm{Ca}^{2+}$ and $\mathrm{Mg}^{2+}$ concentrationpotentiometric titrator 736 GP Titrino from Metrohm was used. The ultra pure nitric acid from the Chempur company was used in digestion stage of the preparation. For protecting samples against contamination the ultra pure nitric acid was applied. Scanning electron microscope (SEM/EDX) manufactured by LEO Electron Microscopy Ltd., England, model $1430 \mathrm{VP}$ was used for topography scrutiny of the surface along with the map of the elements distribution. Diffraction analysis (XRD) was performed with Philips X'Pert device, with the X'Celerator Scientific detector to resolve the qualitative composition.

\section{Result and discussion}

\subsection{Filtration and washing times}

Averaged times of individual filtration and washing stages, as well as of the whole process are given in table 1 . There was a significant reduction in times for all stages, which was caused by the reaction of magnesium hydroxide with a suspended carbon dioxide resulting in hydromagnesite. The appearance of hydromagnesite changes the crystal structure of the precipitate, what makes the filtration and washing process more efficient. This leads to reduction in the time of individual stages of filtration and washing processes. It resulted in a total time reduction by $63 \%$. Thanks to carbonization, it became possible to carry out 2.5 processes compared to the controlled sample. The greatest reduction can be observed for the first two washing phases 71 and $70 \%$ respectively for washing I and II, and the filtration phase $67 \%$. For washing III the reduction was $42 \%$ and this was the lowest result observed. The smaller reduction in the case of washing time III is, however, caused by the filter cake cracking in the absence of water covering and consequently the last drop procedure was used during the experiment. In addition, it can be seen that the standard deviation values were smaller for samples after 
carbonization, what indicates greater process repeatability. In the carbonised test smaller differences between the longest and shortest time in relation to average time than in the reference test were observed.

Table 1. Comparison of filtration and washing times for the reference and carbonization

\begin{tabular}{|c|c|c|c|c|}
\hline Process & Average time [min] & Standard deviation $\sigma$ & Confidence interval & Time reduction [\%] \\
\hline \multicolumn{5}{|c|}{ Reference sample } \\
\hline Filtration & 22.6 & 3.9 & 4.4 & \\
\hline Washing I & 19.9 & 4.6 & 5.2 & \\
\hline Washing II & 16.7 & 5.1 & 5.8 & not applicable \\
\hline Washing III & 36.1 & 10.7 & 12.1 & \\
\hline Entire process & 95.2 & 19.2 & 21.7 & \\
\hline \multicolumn{5}{|c|}{ Carbonization sample } \\
\hline Filtration & 7.5 & 0.2 & 0.2 & 67 \\
\hline Washing I & 5.8 & 0.6 & 0.7 & 71 \\
\hline Washing II & 5.0 & 0.1 & 0.1 & 70 \\
\hline Washing III & 17.2 & 5.1 & 5.8 & 52 \\
\hline Entire process & 35.6 & 5.6 & 6.4 & 63 \\
\hline
\end{tabular}

The results for the soda lye method are given in table 2 .

Table 2. Comparison of filtration and washing times for the reference and carbonization for the lye-sodium process ${ }^{[10]}$

\begin{tabular}{|c|c|c|c|c|}
\hline Process & Average time & Standard deviation $\sigma$ & Confidence interval & Time reduction $[\%]$ \\
\hline \multicolumn{5}{|c|}{ Reference sample } \\
\hline Filtration [min] & 261 & 36 & 29 & \\
\hline Washing I [min] & 127 & 67 & 53 & \\
\hline Washing II [min] & 86 & 42 & 34 & not applicable \\
\hline Washing III [min] & 113 & 30 & 24 & \\
\hline Entire process [min] & 587 & 50 & 40 & \\
\hline \multicolumn{5}{|c|}{ Carbonization sample } \\
\hline Filtration [s] & 235 & 28 & 23 & 99 \\
\hline Washing I [s] & 246 & 10 & 8 & 97 \\
\hline Washing II [s] & 295 & 30 & 24 & 94 \\
\hline Washing III[min] & 65 & 15 & 12 & 42 \\
\hline Entire process [min] & 78 & 15 & 12 & 87 \\
\hline
\end{tabular}

\subsection{Samples analysis}

The analysis results of the basic ion content for sludge and waste brine are included in tables 3 and 4, respectively. Titration analysis of ions was performed using a potentiometric titrator. For solid samples they were reconstituted with ultra pure nitric acid. Data included in tables 3 and 4 are important for the possibility of their subsequent use.

\subsubsection{Analysis of precipitate composition}

An increase in sodium chloride content below $1 \mathrm{mg} / \mathrm{g}$ was observed in samples subjected to carbonization. These values must be taken into account when developing potential fertilizers and food additives. Standard deviation and confidence interval values were comparable. In the case of calcium carbonate, its content decreased by $10.7 \%$. At the same time, the standard deviation and confidence range increased. The content of magnesium compounds increased by $55.9 \%$. There was also an increase in the value of the standard deviation and confidence interval analogously to calcium carbonate. Changes in the content of calcium and magnesium compounds caused a change in the ratio of their content. It fell from 7.9 to 4.6 -it is related to the reaction of magnesium hydroxide with carbon dioxide, what gives hydromagnesite. In addition to the mentioned components, the sediment contains water and mineral impurities originating from the rocks overgrowing the salt deposits and from impurities resulting from the substances used during purification. Mineral impurities, however, 
constitute a very small part of the sediment. The amount of moisture in the samples changed. In the reference sample it amounted to $1.3 \%$, and after carbonization it increased by $3.1 \%$ to the value of $4.4 \%$. Mineral pollution is a small part of the precipitate.

Table 3. Results of determinations for precipitation

\begin{tabular}{cccccc}
\hline \multirow{2}{*}{ Series } & Marked ion & Conversion form & Average form content $[\mathrm{mg} / \mathrm{g}]$ & Standard deviation & Confidence interval \\
\hline \multirow{3}{*}{ Reference } & $\mathrm{Cl}^{-}$ & $\mathrm{NaCl}$ & 7.8 & 0.1 & 0.2 \\
& $\mathrm{Ca}^{2+}$ & $\mathrm{CaCO}_{3}$ & 870 & 1 & 2 \\
& $\mathrm{Mg}^{2+}$ & $\mathrm{Mg}(\mathrm{OH})_{2}$ & 109 & 1 & 2 \\
\multirow{3}{*}{ Carbonization } & $\mathrm{NaCl}$ & $\mathrm{CaCO}_{3}$ & 7.6 & 0.1 & 0.1 \\
& $\mathrm{Ca}^{2+}$ & $\mathrm{Mg}_{5}(\mathrm{OH})_{2}\left(\mathrm{CO}_{3}\right)_{4}$ & 170 & 3 & 5 \\
& & & 3 & 4 \\
\hline
\end{tabular}

\subsubsection{Analysis of byproduct brine composition}

The content of chloride, calcium and magnesium ions that may be in brine byproduct was compared. This brine is a combination of brine from the suspension filtration process and washable liquid (distilled water) with which the filter cake was washed. Differences were observed between the brine from the reference process and brine from the carbonized suspension. Reduction of chloride ion concentration by $2.5 \%$ was observed after carbonization compared to the brine produced in the process without carbonization. A significant increase in magnesium ion concentration by over 6 times was observed. It is caused by a change in the form in which magnesium occurs in the precipitate. Hydromagnesite has greater solubility than magnesium hydroxide. Therefore, there are more magnesium ions in the brine after carbonization in the brine itself, and it is more easily leached out during the three times washing process. No calcium ions were found in both the carbonized and reference systems. This is due to the lower solubility of calcium carbonate than magnesium compounds. The volume of brine formed in this process is small and the inclusion in the stream of raw brine does not pose a threat to the brine purification process using the lime-sodium method.

Table 4. Results of determinations for byproduct brine

\begin{tabular}{ccccc}
\hline Series & Marked ion & Average content & Standard deviation & Confidence interval \\
\hline \multirow{2}{*}{ Reference } & $\mathrm{Cl}^{-}\left[\mathrm{mol} / \mathrm{dm}^{3}\right]$ & 3.86 & 0.01 & 0.01 \\
& $\mathrm{Mg}^{2+}\left[\mathrm{mmol} / \mathrm{dm}^{3}\right]$ & 0.098 & 0.008 & 0.009 \\
Carbonization & $\mathrm{Cl}^{-}\left[\mathrm{mol} / \mathrm{dm}^{3}\right]$ & 3.76 & 0.01 & 0.01 \\
& $\mathrm{Mg}^{2+}\left[\mathrm{mmol} / \mathrm{dm}^{3}\right]$ & 0.617 & 0.005 & 0.005 \\
\hline
\end{tabular}

\subsection{Surface morphology and mapping of the particular elements distribution}

Figure 3 presents sample showing the A and C surfaces morphology and the distribution map of elements B and D for reference sample A and B and subjected to carbonization-C and D. The images showed a large variation in the size of crystallites from very small with diameters of $1 \mu \mathrm{m}$ and smaller to very large-most often of irregular shapes-and maximum diameters of several tens of micrometers and more in individual cases. The smallest of them are mostly magnesium hydroxide compounds for the reference sample and hydromagnesite for the sample after carbonization. Calcium carbonate creates larger crystallites, which are often surrounded by smaller crystallites of magnesium compounds. In addition, the presence of sodium chloride has been confirmed, which often forms large crystallites (figure 3B), it occurs dispersed as an element of other crystallites. The presence of large crystallites results from their greater resistance to leaching. It is possible to remove them by increasing the amount of washes, however, this increases the cost of the entire process and leads to dilution of brine. Brine with a larger volume and lower concentration of sodium chloride is more difficult to manage. Its effect on the raw brine stream depends on their volume ratio. From typical impurities of brine used in industry, silicon compounds (most often silicates and aluminosilicates) have been observed. They come from rocks which are often overgrown with salt deposits and are leached from them along with salt in the leaching process. It creates, like sodium chloride, both large and powdered form crystallites. In contrast to sodium chloride, increasing the number of washes or the 
volume of the washed liquid does not lead to their removal due to their minimal solubility.

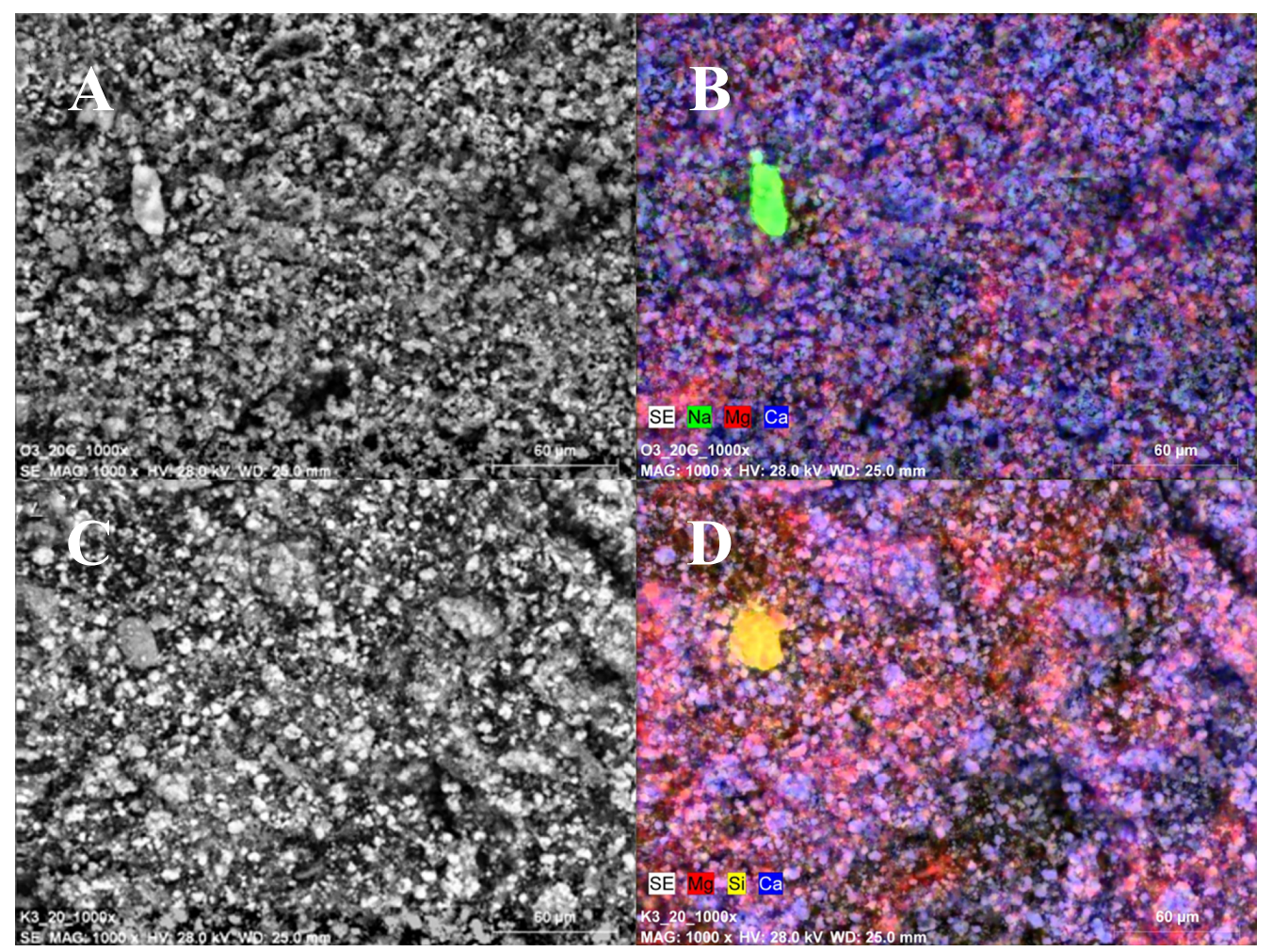

Figure 3. Surface morphology for reference sample A and carbonization sample C. Mapping of the distribution of particular elements for reference sample B and carbonization sample D

\subsection{XRD analysis}

X-ray diffraction was performed in order to qualitatively determine the composition of the tested precipitant before and after carbonization (figure 4). In each case, signals from the three main scalers were observed. In the reference sample it was calcium carbonate, sodium chloride and magnesium hydroxide, and in the case of the carbonised sample it was calcium carbonate, sodium chloride and hydromagnesite. Diffraction peaks with intensity above 1600 and all recognized signals from magnesium hydroxide and hydromagnesite were signed on the diffractogram (figure 4). The highest intensity was observed for diffraction peaks derived from calcium carbonate, which are connected to its definite advantage in composition both in the samples after carbonization and in the reference test. Diffraction peaks were less intense than magnesium hydroxide and sodium chloride due to their smaller percentage in sample. Diffraction peaks derived from sodium chloride can be observed at the following account values $2 \theta$ angle: about 31.6, 56.8 and 84.1 where a signal from calcium carbonate overlaps. The smallest intensity is characterised by diffraction peaks derived from hydromagnesite, what is due both to its lower content than calcium carbonate and also to the characteristics of its signals that are not intense. There were no signals from mineral impurities from spoil rock (XRD database: X'Pert High Score). 


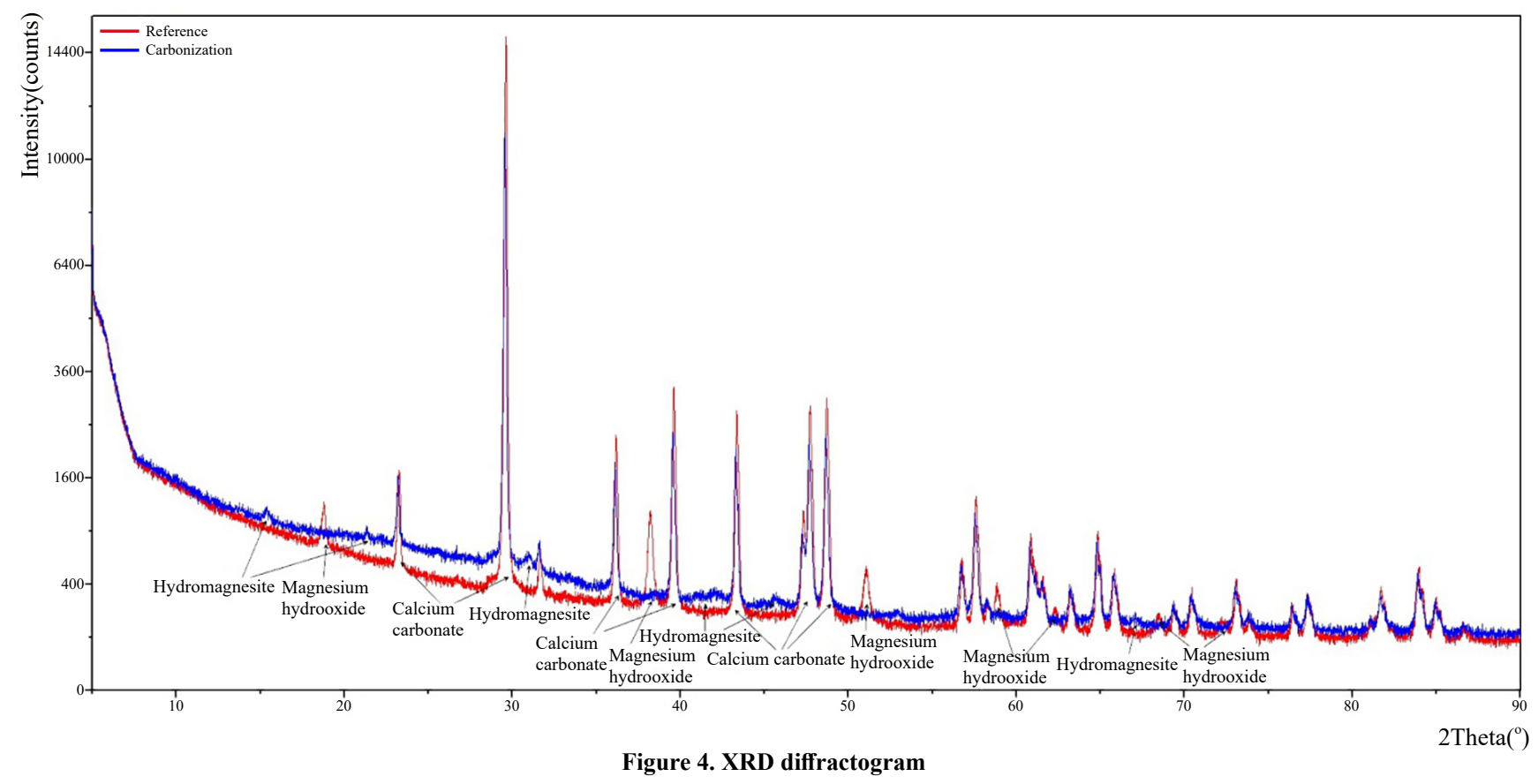

\section{Conclusions}

The content of sodium chloride in the waste from the brine purification process by the lime-sodium method is a significant problem in the management of this industrial waste. Therefore, it is necessary to find a method for its development. Washing the previously filtered sludge three times not only reduces the amount of sodium chloride that previously went to landfill and posed a threat to the surrounding flora and fauna. After reducing the sodium chloride content, it becomes a potentially interesting substrate in the production of fertilizers and mineral feed additives as a source of calcium and magnesium ${ }^{[6]}$.

Thanks to the proposed method of precipitant treatment consisting of its previous exposure to carbon dioxide, it was possible to significantly reduce the filtration and washing time. The total reduction was $63 \%$, and when broken down into individual stages it was $67 \%$ filtration, $71 \%$ in washing I and $70 \%$ in washing II and $52 \%$ in washing III. Compared to the results obtained for the lye-sodium method (table 3), the total reduction was smaller, as was the reduction of filtration and I and II washing times. As for the times, in the case of reference samples with the soda lye method they were definitely longer. In the case of samples after carbonization, the times in the sample from the lime soda method for individual stages were closer to each other than for samples from the lye-sodium where the time of the third washing is much longer.

The brine resulting from the combination of individual fractions from filtration and three times washing for the reference test and the sample after carbonization has parameters that enable the incorporation of this relatively small volume into the raw brine stream. This will make it possible to use the raw material more fully. The same effect was obtained by testing brine from the lye-sodium method ${ }^{[10]}$.

SEM/EDX analysis showed that there are no significant changes in morphology. It also confirmed the presence of typical waste in the form of silicates in this category. However, their presence is not a problem in terms of their further processing.

Thanks to XRD analysis, it was possible to confirm the reaction between the magnesium hydroxide contained in the suspension and the carbon dioxide flowing through it. Other ingredients such as calcium carbonate and sodium chloride do not undergo chemical reactions under these conditions.

The work carried out allowed both to retain waste from brine purification using the lye-sodium and lime-sodium method. Finding a way to manage them is important from this point of view. As part of the research, a method that could be used for suspensions from both types of brine purification methods was proposed. 


\section{Reference}

[1] Anwar MN, Fayyaza A, Sohaila NF, Khokharb MF, Baqara M, Khana WD, Rasoolc K, Rehand M, Nizamid AS. CO capture and storage: A way forward for sustainable environment. Journal of Environmental Management. 2018; 226: 131-144. Available from: https://doi.org/10.1016/j.jenvman.2018.08.009.

[2] Bang JH, Chae SC, Lee S, Kim J, Song K, Kim J, Kim W. Sequential carbonate mineralization of desalination brine for $\mathrm{CO}_{2}$ emission reduction. Journal of $\mathrm{CO}_{2}$ Utilization. 2019; 33: 427-433. Available from: https://doi.org/10.1016/ j.jcou.2019.07.020.

[3] Bang JH, Jang YN, Kim W, Song KS, Jeon CW, Chae SC, Lee SW, Park SJ, Lee MG. Precipitation of calcium carbonate by carbon dioxide microbubbles. Chemical Engineering Journal. 2011; 1(174): 413-420. Available from: https://doi.org/10.1016/j.cej.2011.09.021.

[4] Bukowskii A, Koczorowicz C, Koneczny H, Kowarzyk W, Leszczyński S., Niederliński A, Pawiński E, Radoń F, Strokowski M, Tarczyński L, Walasek W, Wiśniewski E. Soda i produkty towarzyszace. Warszawa: Wydawnictwo Naukowo Techniczne; 1978.

[5] Bunikowska B, Synowiec P. Utilization of a saltworks brine waste. Przemyst Chemiczny. 2005; 1(84): 36-40.

[6] Cang-Song Z, Xiang L, Qi-Ling T, Ying Z, Hui-Ping G, Cheng-Xia H. Soil application of calcium and magnesium fertilizer influences the fruit pulp mastication characteristics of Nanfeng tangerine (Citrus reticulate Blanco cv. Kinokumi). Scientia Horticulturae. 2015; 191: 121-126. Available from: https://doi.org/10.1016/j.scienta.2015.05.008.

[7] Chiang P, Pan S. Carbon Dioxide Mineralization and Utilization. Singapore: Springer; 2017. p.35-50.

[8] Dong C, Song X, Li Y, Liu C, Chen H, Yu J. Impurity ions effect on $\mathrm{CO}_{2}$ mineralization via coupled reactionextraction-crystallization process of $\mathrm{CaCl}_{2}$ waste liquids. Journal of $\mathrm{CO}_{2}$ Utilization. 2018; 27: 115-128. Available from: https://doi.org/10.1016/j.jcou.2018.05.023.

[9] Inventory of U.S. Greenhouse Gas Emissions and Sinks: 1990-2017. United States Environmental Protection Agency. 2019.

[10] Iwański P, Igliński B, Buczkowski R, Cichosz M. Study on impact of Ca-Mg slurry carbonization on brine purification process by the lye-sodium method, VI Int. Scientific Con. Engineering-Through a Young Eye. 2017; 33: 76-100.

[11] Iwański P, Igliński B, Buczkowski R. Modified precipitate from the brine purification process as a potential source of raw material for the fertilizer industry. Przemyst Chemiczny. 2019; 6(98): 1230-1237. Available from: https://doi. org/10.15199/62.2019.8.4.

[12] Kamyk J. Rynek soli w Polsce-stan obecny i perspektywy zmian. Gospodarka Surowcami Mineralnymi. 2008; 4(24): 143-153.

[13] Lee M, Jang YN, Ryu K, Kim W, Bang JH. Mineral carbonation of flue gas desulfurization gypsum for $\mathrm{CO}_{2}$ sequestration. Energy. 2012; 1(47): 370-377. Available from: https://doi.org/10.1016/j.energy.2012.09.009.

[14] Minelgaitè A, Liobikienė G. Waste problem in European Union and its influence on waste management behaviours. Science of The Total Environmental. 2019; 667: 86-93. Available from: https://doi.org/10.1016/j.scitotenv.2019.02.313.

[15] Ponikowska I. O soli i solance w wielu odsłonach. In: Kubiak S. (eds.) Solanka i jej produkty naszym narodowym dobrem, Zeszyty naukowo-historyczne towarzystwa przyjaciót Ciechocinka, Zeszyt nr 1. Ciechocinek; 2008. p.7-13.

[16] Rabald E. Corrosion Guide. Amsterdam: Elsevier; 2012.

[17] Schmidt M, Paul J, Pradier CM. The Thermodynamics of $\mathrm{CO}_{2}$ conversion in carbon dioxide chemistry. Woodhead Publishing; 1994. p.23-30. Available from: https://doi.org/10.1016/B978-1-85573-799-0.50008-X. 